\title{
Screening for fetal congenital heart disease
}

\author{
Alice Pham MD MSc, Mary Melchior MD
}

Cite as: CMAJ 2017 March 27;189:E468. doi: 10.1503/cmaj.160700

\section{Congenital heart disease is the most common cause of infant \\ 1 death and morbidity from birth defects}

Based on population data from the United States, the estimated prevalence of congential heart disease among infants is between 7 and 47 cases per 1000 live births. ${ }^{1}$ Antenatal diagnosis enables multidisciplinary patient counselling and referral to a tertiary care obstetrical centre.

\section{Referral for fetal echocardiography should be made in cases where nuchal translucency is above the 99th percentile}

First- or second-trimester serum screening tests and detailed ultrasonography at 18-20 weeks of gestation are offered to all pregnant women in Canada as screening for aneuploidy and congenital anomalies. ${ }^{2} \mathrm{~A}$ first-trimester screen for aneuploidy includes measurement of nuchal translucency between 11 and 14 weeks of gestation. Major cardiac defects will be detected in 1 in 16 fetuses with nuchal translucency above the 99th percentile $(\geq 3.5 \mathrm{~mm}){ }^{2}$

\section{3}

\section{Most cases of congenital heart disease occur in low-risk populations}

An abnormal cardiac screen at 18-20 weeks routine ultrasonography is predictive of congenital heart disease and follow-up with fetal echocardiography is recommended. This should include a four-chamber view of the heart and outflow tracts, which will detect $60 \%-80 \%$ of cardiac defects. ${ }^{3}$ However, up to $30 \%$ of lesions remain unanticipated at birth. ${ }^{4}$

\section{Both maternal and fetal factors may prompt referral for fetal}

echocardiography

Prompt referral for fetal echocardiography should be made when the following maternal indications are present: first-degree relative with congenital heart disease, maternal systemic disease (e.g., diabetes, lupus), in vitro fertilization, exposure to teratogens and familial inherited disorders (e.g., Marfan syndrome). Fetal indications that should prompt referral include chromosomal abnormality, extracardiac anomalies, hydrops, arrhythmias, monochorionic twins and polyhydramnios. ${ }^{4}$

\section{Some lesions can be treated antenatally}

A large population-based study in the US found that neonatal mortality ranged from $5.4 \%$ to $26.9 \%$ and infant mortality from $12.9 \%$ to $44.8 \%$ across eight specific congenital heart diseases. ${ }^{5}$ One-third of cases of congenital heart disease will require catheter-based or surgical intervention at any point before or after birth, with survival rates varying by disease complexity. ${ }^{6}$ Conditions amenable to fetal cardiac catheter intervention include aortic stenosis with evolving hypoplastic left heart syndrome, mitral valve dysplasia syndrome with mitral regurgitation and aortic stenosis, hypoplastic left heart syndrome with restrictive/ intact atrial septum and pulmonary atresia with intact ventricular septum. ${ }^{4}$

\section{References}

1. Parker E, Mai CT, Canfield MA, et al. Updated national birth prevalence estimates for selected birth defects in the United States, 2004-2006 [Part A]. Birth Defects Res A Clin Mol Teratol 2010;88:1008-16.

2. Chitayat D, Langlois S, Wilson RD; Genetics Committee of the Society of Obstetricians and Gynaecologists of Canada; Prenatal Diagnosis Committee of the Canadian College of Medical Geneticists. J Obstet Gynaecol Can 2011; 33:736-50.

3. Simpson LL. Screening for congenital heart disease. In: Queenan JT, Spong CY, Lockwood CJ. Queenan's management of high-risk pregnancy: an evidence-based approach. 6th ed. Malden (MA): John Wiley \& Sons; 2012:47-54.

4. Donofrio MT, Moon-Grady AJ, Hornberger LK, et al. Diagnosis and treatment of fetal cardiac disease: a scientific statement from the American Heart Association. Circulation 2014;129:2183-242.

5. Wang Y, Liu G, Canfield MA, et al. Racial/ethnic differences in survival of United States children with birth defects: a population-based study. J Pediatr 2015;166: 819-26.

6. Marino BS, Lipkin PH, Newburger JW, et al. Neurodevelopmental outcomes in children with congenital heart disease: evaluation and management: a scientific statement from the American Heart Association. Circulation 2012;126:1143-72.

Competing interests: None declared.

This article has been peer reviewed.

Affiliations: Department of Obstetrics and Gynecology, St. Joseph's Health Centre, Toronto, Ont.

Correspondence to: Alice Pham, alice.pham@ mail.utoronto.ca 